\section{Evaluation of the Germination Potential of Citrus Seeds during the Harvesting Season}

\author{
Vladimir Orbović, Manjul Dutt' ${ }^{\mathbf{1}}$, and Jude W. Grosser \\ Citrus Research and Education Center, University of Florida/IFAS, 700 \\ Experiment Station Road, Lake Alfred, FL 33850
}

Additional index words. citrus, seeds, germination

Abstract. The effects of fruit age on the seed quality and germination percentage of 'Duncan' and 'Flame' grapefruit and 'Hamlin' sweet orange were investigated. Our results suggested that seed germination varied from $98 \%$ to $100 \%$ for the two grapefruit cultivars and $85 \%$ to $100 \%$ for 'Hamlin' regardless of time of harvest. Within the first 5 months of the harvest season, chilling of 'Duncan' and 'Hamlin' seeds at $4{ }^{\circ} \mathrm{C}$ for 7 days after fruit sampling resulted in a lower germination percentage only with the 'Hamlin' seeds. Seed moisture content of all three cultivars varied slightly through the season and remained steady at $60 \%$ and $70 \%$ for batches of fresh seeds stored at room temperature or at $4{ }^{\circ} \mathrm{C}$. Our results suggest that high seed viability and germination percentage can allow the use of these seeds for experimentation regardless of the time the fruit were picked during the harvest season.

Despite recent declines, citrus remains the dominant fruit crop produced in the state of Florida. As a result of the introduction of cultivars maturing at different times, citrus harvesting season can span almost 9 months from early September with the early grapefruit cultivars to the middle of June for the late sweet orange cultivars. During the picking season, many of the fruit physiological characteristics including color development, sugar content, and acid levels are followed because they affect the juice quality and marketability of fruit destined for fresh consumption. However, effects of seasonal changes of these commercially important features on seed viability and seedling vigor from those seeds have not been previously investigated.

Citrus seed biology, including morphology and viability, storage conditions, and treatments to improve rate and synchrony of germination, was studied exhaustively during the 1940s and 1980s (reviewed by Castle, 1981). Seed behavior and physiological studies are important because preservation of seed vigor in a tropical tree crop like citrus is important. Seed vigor affects the overall seed viability and this is directly dependent on several factors such as the moisture content, storage temperature, relative humidity, and carbon dioxide, and oxygen pressures in the storage environment (Fawusi, 1979). In a few studies, germination percentage of 'Red Blush' grapefruit and sour orange seeds extracted from fruit picked at different times were compared (Fucik, 1974, 1978). However, these data were recorded only during the early part of the season (September), and

Received for publication 9 May 2013. Accepted for publication 1 July 2013.

${ }^{1}$ To whom reprint requests should be addressed; e-mailmanjul@ufl.edu. with the age of fruit throughout the fruit harvesting season. subsequent germination percentages as well viability, an fruit maturity on seed and seedling uniformity and concluded uniformity in the height of seedling seeds (Chilembwe et al., 1992; Fucik, 1978). (t) was not known how the sec season in Florida.

We have recently reported that cultivars exhibit variation in the capacity for shoot morphogenesis and transformability throughout the harvest season (Orbović et al., 2011). The objective in this study was
to correlate seed germination and viability

\section{Materials and Methods}

All fruit were collected from trees growing at the Citrus Research and Education Center in Lake Alfred, FL. Seeds from two grapefruit cultivars, Duncan and Flame (Citrus paradisi Macf.), and the sweet orange cultivar Hamlin (Citrus sinensis L. Osbeck) were used in this study. An effort was made to pick fruit similar in size and color. The seeds were extracted immediately after fruit harvest. All fruit were sampled on a monthly basis during the harvesting season. 'Flame' was sampled at eight monthly intervals: September to April; 'Duncan' was sampled nine times: October to June; and 'Hamlin' were sampled seven times: December to June. Fruit were considered to be of inappropriate quality when precocious germination was observed in the grapefruits (Fig. 1) or fruits had begun to fall off the tree in 'Hamlin' sweet orange.

'Duncan' and 'Hamlin' seeds collected during the first month (October for 'Duncan' and December for 'Hamlin') were divided into three batches. The first batch of seeds was surface-sterilized by keeping them for 10 min in water maintained at $52{ }^{\circ} \mathrm{C}$ (Bridges and Youtsey, 1966; Klotz et al., 1960) and dipping them in $1 \% 8$-hydroxyquinoline (8HQ) sulfate for $3 \mathrm{~min}$ (Klotz, 1978). Seeds were then air-dried and stored in plastic petri dishes at $4{ }^{\circ} \mathrm{C}$ for 10 weeks. The second batch of seeds was also disinfested in warm water and $8 \mathrm{HQ}$, air-dried, packaged, but later stored at room temperature $\left(25 \pm 2{ }^{\circ} \mathrm{C}\right)$ for 4 weeks. The third batch of seeds was peeled and surface-sterilized by shaking for $15 \mathrm{~min}$ in a $20 \%$ solution of commercial bleach (percent hypochlorite) and rinsed with sterile water three times (10 min each rinse). Seeds from the first two batches were subsequently processed as the third batch of seeds. For all other collection periods except the first, seeds of all three cultivars were peeled, surfacesterilized in bleach, and planted immediately. Two peeled seeds were placed per glass tube containing $18 \mathrm{~mL}$ of solid Murashige and Skoog medium. The tubes were sealed with Nescofilm and left in the dark at room temperature $\left(25 \pm 4{ }^{\circ} \mathrm{C}\right)$ for 4 weeks. During this

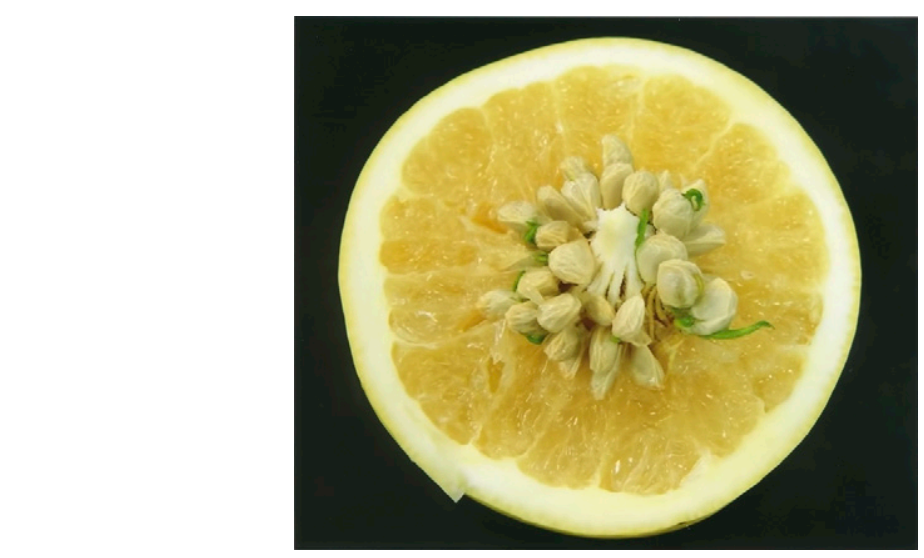

Fig. 1. Vivipary in 'Duncan' grapefruit. 
period, seedlings germinated from the seeds and grew to be 10 to $12 \mathrm{~cm}$ long. The seedlings were exposed to white light for an additional $5 \mathrm{~d}$ before they were used for transformation experiments and germination percentage recorded for each population. The effect of 7-d chilling on seed germination was tested for the first 5 months of the picking season.

Moisture content measurements. Seed moisture content was determined by a low constant temperature oven method for tree seeds as described by the International Seed Testing Association (1993) and expressed on a fresh weight basis.

Statistical analyses. Seed germination percentages were averaged for the study period and are presented with sDs. Before they were statistically analyzed, values for germination were converted into different values through arcsine transformation. Significant differences among treatments were analyzed using Duncan's multiple range test at $P<0.05$ (SAS Institute, Cary, NC).

\section{Results and Discussion}

For all three cultivars, the seed germination percentage was similar and did not change significantly throughout the picking season (Table 1). From September to April,

Table 1. Seed germination in 'Flame' and 'Duncan' grapefruit and 'Hamlin' sweet orange. ${ }^{z}$

\begin{tabular}{lrcc}
\hline & \multicolumn{3}{c}{ Cultivar } \\
\cline { 2 - 4 } Harvest time & Flame & Duncan & Hamlin \\
\hline September & 99.3 & \\
October & 99.0 & 100.0 \\
November & 99.5 & 100.0 & \\
December & 100.0 & 100.0 & 91.7 \\
January & 99.3 & 100.0 & 96.3 \\
February & 100.0 & 100.0 & 95.7 \\
March & 99.3 & 98.0 & 92.9 \\
April & 100.0 & 100.0 & 94.1 \\
May & \multicolumn{4}{c}{100.0} & 85.7 \\
June & 100.0 & 100.0 \\
Average & $99.6 \mathrm{~A}$ & $99.8 \mathrm{~A}$ & $93.8 \mathrm{~B}$ \\
SD & 0.4 & 0.7 & 4.5 \\
\hline zAll rates are presented as percentages. \\
Values followed by the same upper case letter did \\
not differ significantly at $P<0.05$ using Duncan's \\
multiple range test.
\end{tabular}

Table 2. Seed germination in 'Duncan' grapefruit and 'Hamlin' sweet orange after storage of the seeds at $4{ }^{\circ} \mathrm{C} .{ }^{\mathrm{z}}$

\begin{tabular}{llc}
\hline & \multicolumn{2}{c}{ Cultivar } \\
\cline { 2 - 3 } Storage duration & Duncan & Hamlin \\
\hline 2 weeks & 100.0 & 94.9 \\
4 weeks & 100.0 & 90.8 \\
6 weeks & 100.0 & 88.8 \\
8 weeks & 100.0 & 78.2 \\
10 weeks & 95.0 & 81.5 \\
Average & $99.0 \mathrm{~A}$ & $86.8 \mathrm{C}$ \\
SD & 2.2 & 6.9 \\
\hline
\end{tabular}

z'Duncan' grapefruit seeds were harvested during October, whereas 'Hamlin' sweet orange seeds were harvested in December. All rates are presented as percentages.

Values followed by the same upper case letter did not differ significantly at $P<0.05$ using Duncan's multiple range test.
'Flame' seeds exhibited an average germination of $99.6 \% \pm 0.4 \%$. For 'Duncan' seeds, the average germination was $99.8 \% \pm 0.7 \%$ from October to June. The germination of 'Hamlin' seeds during December to June was lower $(93.8 \% \pm 4.5 \%)$ when compared with either of the grapefruits. Storage of 'Duncan' seeds at $4{ }^{\circ} \mathrm{C}$ for 2 to 10 weeks after extraction did not decrease their germination $(99.0 \% \pm 2.2 \%)$ as compared with freshly extracted seeds. Refrigeration of 'Hamlin' seeds did however result in a slightly lower germination rate $(86.7 \% \pm 6.9 \%)$ than freshly extracted seeds (Table 2).

The differences observed between the average germination percentage of grapefruit and sweet orange seeds were small but statistically significant, suggesting an important distinction in mechanisms controlling germination in these two species. Germination differences between citrus cultivars have been previously reported. Sour orange seeds were observed to have a lower germination percentage than grapefruit seeds (Fucik, 1974, 1978 ). We observed vivipary in $\approx 25 \%$ of the grapefruit seeds by the end of the picking season (May and June; Fig. 1). This did not affect the in vitro viability of the remaining seeds and their ability to germinate. Earlier studies have followed and correlated maturation of seeds and their germination in the early parts of the season. On maturing in
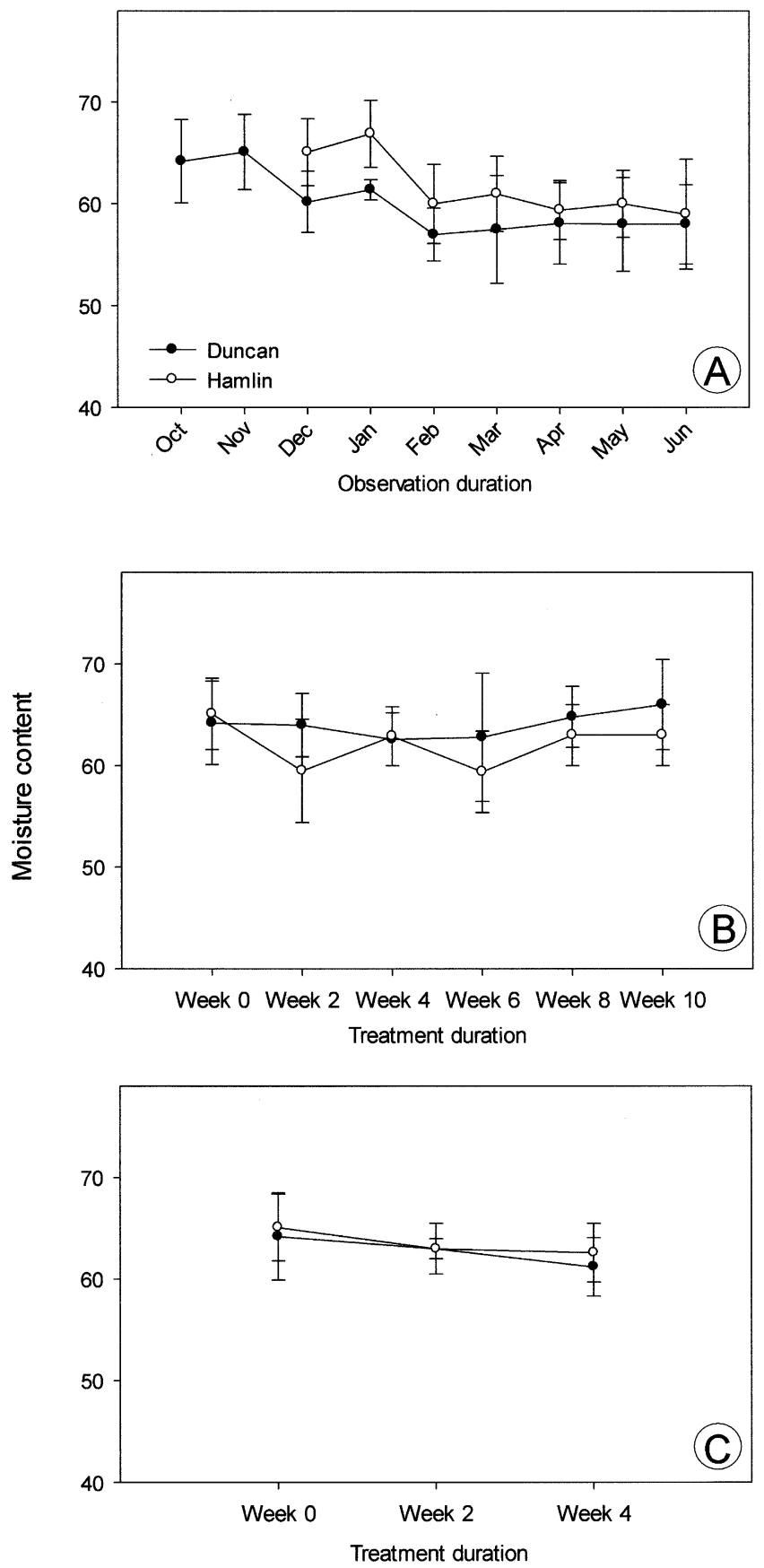

Fig. 2. Moisture content of citrus seeds: (A) freshly harvested seeds, treated with 8-hydroxyquinoline; (B) seeds stored at $4{ }^{\circ} \mathrm{C}$; and $(\mathbf{C})$ seeds stored at room temperature. Vertical bars represent $\pm \mathrm{SE}$. 
September, seeds of both 'Red Blush' grapefruit and sour orange were $\approx 330 \mathrm{mg}$ and $125 \mathrm{mg}$, respectively. At that time, seeds of these two cultivars also reached the maximum germination percentage (Fucik, 1974, 1978). Our study confirms previous reports and shows that once seeds reach maturity, their viability remains high and almost constant throughout the whole harvesting season.

Seed moisture content also varied slightly throughout the season (Fig. 2). Moisture content ranged from a high of $65.1 \% \pm 3.7 \%$ in November to $57.0 \% \pm 2.6 \%$ in February for 'Duncan' and $66.9 \% \pm 3.3 \%$ in January to $59.0 \% \pm 5.4 \%$ in June for 'Hamlin' (Fig. 2A). There was also no significant variation in the moisture content in either 'Duncan' or 'Hamlin' seeds treated with $8 \mathrm{HQ}$ and subsequently stored at $4{ }^{\circ} \mathrm{C}$ for 10 weeks (Fig. 2B). Moisture content ranged from $64.2 \% \pm 4.1 \%$ at the start of the experiment to $66.0 \% \pm 3.0 \%$ at the end of the experiment for 'Duncan' and from $65.1 \% \pm 3.5 \%$ to $63.0 \% \pm 3.0 \%$ for 'Hamlin'. Similarly, after storage at room temperature for 4 weeks, moisture content ranged from $64.2 \% \pm 4.3 \%$ to $61.2 \% \pm 2.9 \%$ for 'Duncan' and $65.1 \% \pm 3.3 \%$ to $62.6 \% \pm 2.9 \%$ for 'Hamlin' (Fig. 2C).

Citrus seed moisture content has been correlated with seed germination with lower moisture levels being inhibitory for seed germination (Hassanein and Azooz, 2003). This happens when excessive desiccation disrupts cell membranes causing solute leakage from the cells (Powell and Matthews, 1980). When such seeds with damaged internal tissue are placed under conditions favorable for germination, they will not germinate. In both grapefruits and sweet oranges, higher moisture content in the seeds reduces their storage life. Storage of these seeds is therefore recommended at low humidity conditions. On the other hand, seeds do not germinate if moisture content is reduced to less than $6 \%$. The moisture content of 'Duncan' and 'Hamlin' seeds used in our study decreased slightly as the season progressed but stayed at levels that were high enough not to affect germination. According to Ferreira (1969), germination of citrus seeds is delayed because they are dried for a longer time. The viability of citrus rootstock seeds is also reduced with prolonged drying (Nauer, 1981). Similar results have also been observed in studies with seeds of Citrus ladanifer (Perez-Garcia, 1997). Citrus seeds have also been reported to possess recalcitrant storage behavior (King and Roberts, 1980). It has been shown that seeds of several species can survive considerable desiccation, but, nevertheless, do not show strictly orthodox seed storage behavior (Ellis et al., 1990; Hong and Ellis, 1990). The storage behavior of seeds used in our study (Fig. 2) did not follow the pattern as defined for orthodox or recalcitrant seeds (Roberts, 1973). Therefore, such behavior can be described as intermediate, similar to one that occurs in Coffea sp. (Ellis et al., 1990). The appearance of vivipary in grapefruit seeds that we observed at the end of the season is a physiological manifestation of the change of hormone balance in fruit. To a high extent, vivipary is controlled by the slow decrease of abscisic acid (ABA) levels in seeds (Farnsworth, 2000). Thus, our data suggest that the change in ABA levels in older seeds did not affect their subsequent germination in vitro. Another possibility is that ABA levels did not change in seeds that did not germinate within the fruit.

When epicotyl segments derived from in vitro seedlings of these three cultivars were used in experiments for Agrobacteriummediated transgenic plant production, their ability to produce shoots as well as incorporate our gene of interest after transformation varied according to the cultivar (Orbović et al., 2011). The shoot morphogenesis capacity also changed significantly for all three cultivars during the picking season. Responsiveness of explants to hormones supplied exogenously as components of tissue culture media is related to physiological state and hormonal balance within the seedlings. Because those seedlings germinated from seeds treated the same way as those in experiments presented here, our results suggest that the hormones mediating seed germination are different from those rendering the tissue capable for shoot morphogenesis.

We can conclude that seed viability and germination percentage for 'Duncan', 'Flame', and 'Hamlin' cultivars remain high throughout the harvest season. Properly treated seeds of these cultivars can be stored at $4{ }^{\circ} \mathrm{C}$ for a period of 10 weeks without any adverse effect. Stored seeds should be amenable to any experimentation during this period.

\section{Literature Cited}

Bridges, G.D. and C.O. Youtsey. 1966. Improved disease control through hot water treatment of citrus seed. Proc. Fla. State Hort. Soc. 79:114 115.

Castle, W.S. 1981. A review of Citrus seed biology and its relationship to nursery practices. Proc. Intl. Soc. Citricult. 1:113-119.
Chilembwe, E.H.C., W.S. Castle, and D.J. Cantliffe. 1992. Grading, hydrating, and osmotically priming seed of four Citrus rootstocks to increase germination rate and seedling uniformity. J. Amer. Soc. Hort. Sci. 117:368-372.

Ellis, R.H., T.D. Hong, and E.H. Roberts. 1990. An intermediate category of seed storage behaviour? I. Coffee. J. Expt. Bot. 41:1167-1174.

Farnsworth, E. 2000. The ecology and physiology of viviparous and recalcitrant seeds. Annu. Rev. Ecol. Syst. 31:107-138.

Fawusi, M.O.A. 1979. Viability of citrus seeds as influenced by the methods of drying and storage temperatures. Nigerian J. Sci. 13:313-322.

Ferreira, J.J. 1969. Loss of germination capacity in citrus species. Rev. Facul. Agron. Veter. da Buenos Aires. 17:51-55

Fucik, J.E. 1974. Grapefruit seed viability and germination. J. Rio Grande Valley Hort. Soc. 28:140-142.

Fucik, J.E. 1978. Sources of variability in sour orange seed germination and seedling growth. Proc. Intl. Soc. Citricult. 1:141-143.

Hassanein, A.M. and M.M. Azooz. 2003. Propagation of Citrus reticulata via in vitro seed germination and shoot cuttings. Biol. Plant. 47:173-177.

Hong, T.D. and R.H. Ellis. 1990. A comparison of maturation drying, germination and desiccation tolerance between developing seeds of Acer pseudoplatanus L. and Acer platanoides L. New Phytol. 116:589-596.

International Seed Testing Association. 1993. Rules for testing seeds: Rules 1993. Seed Sci. Technol. 21(suppl.):1B259.

King, M.W. and E.H. Roberts. 1980. The desiccation response of seeds of Citrus limon L. Ann. Bot. (Lond.) 45:489-492.

Klotz, L.J. 1978. Fungal, bacterial, and nonparasitic diseases and injuries originating in the seedbed, nursery and orchard, p. 1-66. In: Reuther, W., E.C. Calavan, and G.E. Carmen (eds.). The citrus industry, Vol. IV. Univ. Calif., Berkeley, CA.

Klotz, L.J., T.A. De Wolfe, C.N. Oistacher, E.M. Naver, and J.B. Carpenter. 1960. Heat treatments to destroy fungi in infected seeds and seedlings of citrus. Plant Dis. Rpt. 44:858 861.

Nauer, E.M. 1981. Drying of rootstock seeds delay germination. Citrograph 66:204-206.

Orbović, V., M. Dutt, and J.W. Grosser. 2011 Seasonal effects of seed age on regeneration potential and transformation success rate in three citrus cultivars. Sci. Hort. 127:262-266.

Perez-Garcia, F. 1997. Germination of Citrus ladanifer seeds in relation to parent material. Plant Ecol. 133:57-62.

Powell, A.A. and S. Matthews. 1980. The significance of damage during imbibition to the field emergence of pea (Pisum sativum). J. Agron. 94:35-38.

Roberts, E.H. 1973. Predicting the storage life of seeds. Seed Sci. Technol 1:499-514. 